\title{
A scoping review of the perceptions of death in the context of organ donation and transplantation
}

\author{
George Skowronski ${ }^{1}{ }^{*}$, Anil Ramnani ${ }^{2}$, Dianne Walton-Sonda ${ }^{3}$, Cynthia Forlini ${ }^{4}$, Michael J. O'Leary ${ }^{5}$, \\ Lisa O'Reilly' ${ }^{6}$, Linda Sheahan ${ }^{1}$, Cameron Stewart ${ }^{7}$ and lan Kerridge ${ }^{1,8}$
}

\begin{abstract}
Background: Socio-cultural perceptions surrounding death have profoundly changed since the 1950s with development of modern intensive care and progress in solid organ transplantation. Despite broad support for organ transplantation, many fundamental concepts and practices including brain death, organ donation after circulatory death, and some antemortem interventions to prepare for transplantation continue to be challenged. Attitudes toward the ethical issues surrounding death and organ donation may influence support for and participation in organ donation but differences between and among diverse populations have not been studied.
\end{abstract}

Objectives: In order to clarify attitudes toward brain death, organ donation after circulatory death and antemortem interventions in the context of organ donation, we conducted a scoping review of international English-language quantitative surveys in various populations.

Study appraisal: A search of literature up to October 2020 was performed, using multiple databases. After screening, 45 studies were found to meet pre-specified inclusion criteria.

Results: 32 studies examined attitudes to brain death, predominantly in healthcare professionals. In most, around $75 \%$ of respondents accepted brain death as equivalent to death of the person. Less common perspectives included equating death with irreversible coma and willingness to undertake organ donation even if it caused death. 14 studies examined attitudes to organ donation following circulatory death. Around half of respondents in most studies accepted that death could be confidently diagnosed after only $5 \mathrm{~min}$ of cardiorespiratory arrest. The predominant reason was lack of confidence in doctors or diagnostic procedures. Only 6 studies examined attitudes towards antemortem interventions in prospective organ donors. Most respondents supported minimally invasive procedures and only where specific consent was obtained.

Conclusions: Our review suggests a considerable proportion of people, including healthcare professionals, have doubts about the medical and ethical validity of modern determinations of death. The prognosis of brain injury was a more common concern in the context of organ donation decision-making than certainty of death.

*Correspondence: mavidica1@gmail.com

1 Sydney Health Ethics, University of Sydney, Sydney, Australia

Full list of author information is available at the end of the article

\section{Background}

Longstanding and almost universal socio-cultural perceptions surrounding death were radically changed by the more-or-less simultaneous emergence of several medical technologies in the 1950s-60s. These included mechanical ventilation and the development of modern 
intensive care units, cardiopulmonary resuscitation and defibrillation.

The concept of brain death (BD) has not been accepted without controversy [1]. Concerns revolve around the fundamental question of whether brain death is a manifestation of biological death, but also in regard to the clinical process by which brain death is determined and whether there is a requirement to confirm death of the whole brain. Over the decades there have been numerous publications on these matters [2,3]. While most of the debate has been conducted in the scientific and ethical literature, in recent years there have been a number of international legal challenges to its validity in individual cases [4,5]. Documentation of the World Brain Death Project [6], developed by international consensus, has improved uniformity in the diagnostic process for $\mathrm{BD}$, but it has done little to address fundamental philosophical questions around its meaning and significance [7].

Although early transplants involved donors whose heartbeat and breathing had ceased, brain death subsequently became the predominant path to organ donation, as it increased both the range and quality of donated organs. However, since around 2005 there has been a resurgence of interest in utilising donors dying following cardio-respiratory failure because (1) the rapidly increasing demand for transplantation greatly exceeded the supply of suitable organs from BD donors, and (2) it was anticipated that peri-mortem retrieval of vital organs for transplantation from people declared dead following circulatory failure would not violate what has become known as the 'dead donor rule' (DDR)-the notion that vital organs can only be removed from persons who have already been declared dead [8]. 'Donation after Circulatory Determination of Death' (DCDD) requires that organ retrieval occurs rapidly, before irreversible ischaemic injury can supervene, but in order to confirm that death has occurred prior to commencement of retrieval surgery, strict time constraints around the cardio-respiratory signs of death are imposed, based on the likelihood of auto-resuscitation.

To mitigate against ischaemic damage and improve outcomes following organ transplantation a range of interventions with varying degrees of invasiveness, which are not part of usual end-of-life care, can be undertaken in DCDD patients prior to the declaration of death. While these so-called "antemortem interventions" are permitted in some jurisdictions, relying ethically on arguments linking them with the patient's best interests based on their "interest" in being a donor, they are controversial because they are arguably more frequently performed primarily in the organ recipient's interests, rather than those of the donor in the context of quality end of life care.
Studies that have examined attitudes to BD have generally been small and confined to restricted professional, cultural and regional populations. Many studies also tend to conflate support for OD and physiological comprehension of BD with moral 'support' for BD and DCDD, assuming that any concerns about them reflect a knowledge gap rather than a values-based rejection [9-14]. Consequently, individual studies may fail to provide unbiased and comprehensive accounts of the range of ethical views regarding $\mathrm{BD}$ or DCDD and related attitudes in relevant communities. Both of these perspectives are needed to ensure that policies and protocols around brain death, DCDD and organ donation are consistent with the values and attitudes of donors, healthcare professionals and the general public. In order to clarify these perspectives, we conducted a scoping review of studies that have examined the acceptance and understanding of $\mathrm{BD}$ and $\mathrm{DCDD}$, including related antemortem interventions, in various populations, and their relation to decision-making in the context of organ donation.

\section{Methods \\ Research methodology}

A scoping review methodology was chosen because it accommodates the heterogeneity in study aims and methods used in international studies examining the acceptance and understanding of BD and DCDD in the context of organ transplantation. Additionally, while systematic reviews require methodological uniformity and are most useful where outcomes measures are easily defined and measured, scoping reviews can reveal areas of divergence and debate, identify gaps in what is known about a field, issue or question and enable exploration of underlying or foundational concepts or ideas $[15,16]$. The scoping review was guided by the PRISMA protocol with conceptualisation of the research question as "What quantitative evidence is available regarding the acceptance of and attitudes towards the concepts of BD, DCDD and the DDR, and how these relate to attitudes and decision-making regarding organ donation?" Assessment of relevance was done following the 'methodologyissue-participant approach' described by Strech et al. [17] (Table 1).

\section{Literature search}

The search strategy included a combination of synonyms and controlled vocabularies from Medical Subject Headings (MeSH), EmTree, Thesaurus of Psychological Index Terms and CINAHL Subject Headings. The search was conducted on Medline (OVID) and replicated using Embase (OVID), PubMed, EmCare for Nursing (OVID), PsycINFO (OVID), Cochrane and CINAHL databases using truncations and Boolean operators. 
Table 1 Inclusion and exclusion criteria applied to studies in the 'eligibility' step of the PRISMA protocol

\begin{tabular}{|c|c|c|}
\hline & Inclusion criteria & Exclusion criteria \\
\hline Study characteristics & $\begin{array}{l}\text { Written in English } \\
\text { Published as full-text article in an indexed journal } \\
\text { Sufficient details about methodology and results available }\end{array}$ & $\begin{array}{l}\text { Discussion or review articles } \\
\text { Studies using qualitative methodology } \\
\text { Articles published in a language other than English }\end{array}$ \\
\hline Participants & $\begin{array}{l}\text { Members of the general public } \\
\text { Students regardless of discipline } \\
\text { Healthcare professionals }\end{array}$ & \\
\hline Data & $\begin{array}{l}\text { Studies reporting quantitative data on the attitudes and beliefs } \\
\text { of relevant populations on brain death, circulatory death, and } \\
\text { perimortem interventions, in the context of organ donation }\end{array}$ & $\begin{array}{l}\text { Studies Only testing knowledge or awareness of concepts related } \\
\text { to brain death, circulatory death, dead donor rule, organ dona- } \\
\text { tion } \\
\text { Studies reporting data on emotional responses to death as an } \\
\text { event } \\
\text { Studies collecting data on attitudes toward organ donation } \\
\text { alone }\end{array}$ \\
\hline
\end{tabular}

The full search strategy is detailed in the Additional file 1.

Studies were identified by database searches following deduplication. The studies were screened by the authors on the basis of their abstracts, which were then filtered for relevance according to predetermined inclusion and exclusion criteria by two authors per article (Table 1 ). Disagreements were reconciled by discussion within pairs or by a third author if disagreements persisted.

Hand searches of the grey literature and of reference lists in relevant articles were also performed in order to minimise the risk of missed studies.

\section{Date limits}

The study examined papers published up to October 2020, with the earliest appearing in 1972.

\section{Quality assessment}

Methodologic quality was assessed using a checklist proposed by Roever [18]. Each study was assessed independently by two authors. Studies meeting the inclusion criteria were further subjected to risk of bias assessment based on criteria developed by Agarwal et al. [19] Because of the heterogeneity of study populations, methods, instruments and outcome measures, formal metaanalysis was not conducted.

\section{Results}

An initial database search yielded 2347 abstracts. A further 139 were identified from other sources. After screening, 138 papers were reviewed in detail (Fig. 1). This yielded a final list of 45 included studies.

Table 2 shows the risk of bias assessment for the 45 included studies. 34 studies were assessed as having a low or very low risk of bias whereas 12 studies had a high risk of bias. This assessment indicates that the empirical evidence included in our scoping review is overall of good quality. However, there is a strong preponderance of studies from North America (Fig. 2).

Table 3 summarises the themes explored by included studies, and Table 4 lists the main findings of each.

\section{Attitudes to BD}

32 studies examined attitudes to BD. The large majority surveyed healthcare professionals, with a second group involving university students. Only 6 studies surveyed the general public, one of which was mainly in the form of a satisfaction survey among donor families. 19 studies directly addressed whether acceptance of BD was broadly consistent with the death of a person. In most populations studied, around $75 \%$ accepted this proposition, though there was considerable variation. Several studies noted substantial numbers of respondents who supported a 'higher brain' concept of death, while others noted a willingness to proceed with OD even where respondents believed a hypothetical patient was still alive. Five studies noted either distrust of doctors or distrust of clinical techniques of BD determination.

\section{Studies involving healthcare workers}

One of the largest studies [20] was conducted in 245 hospitals across 11 countries, involving critical care staff reporting attitudes towards brain death and its correlation with organ donation. This revealed that support for the statement 'Brain death is a valid determination of death' was highest in Western Europe and lowest in Japan (Norway 94.7\%, Belgium 89.7\%, Croatia 67.4\%, Japan $36.4 \%)$. Acceptance of the BD concept was significantly lower among nursing staff (77.4 $\pm 17.3 \%)$ compared with physicians $(87.2 \pm 9.75 \%)$. Average national medical and nursing staff acceptance of BD showed a strong positive correlation with national organ donation rates.

In North America, Youngner et al. [21], in a 1989 Cleveland study, interviewed 195 medical and nursing 


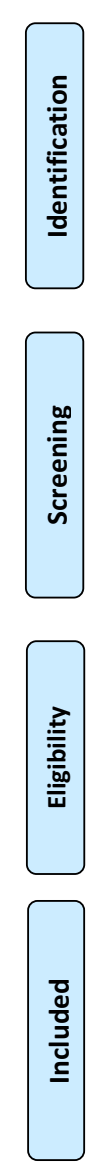

Records identified through

database searching

$(n=2347)$
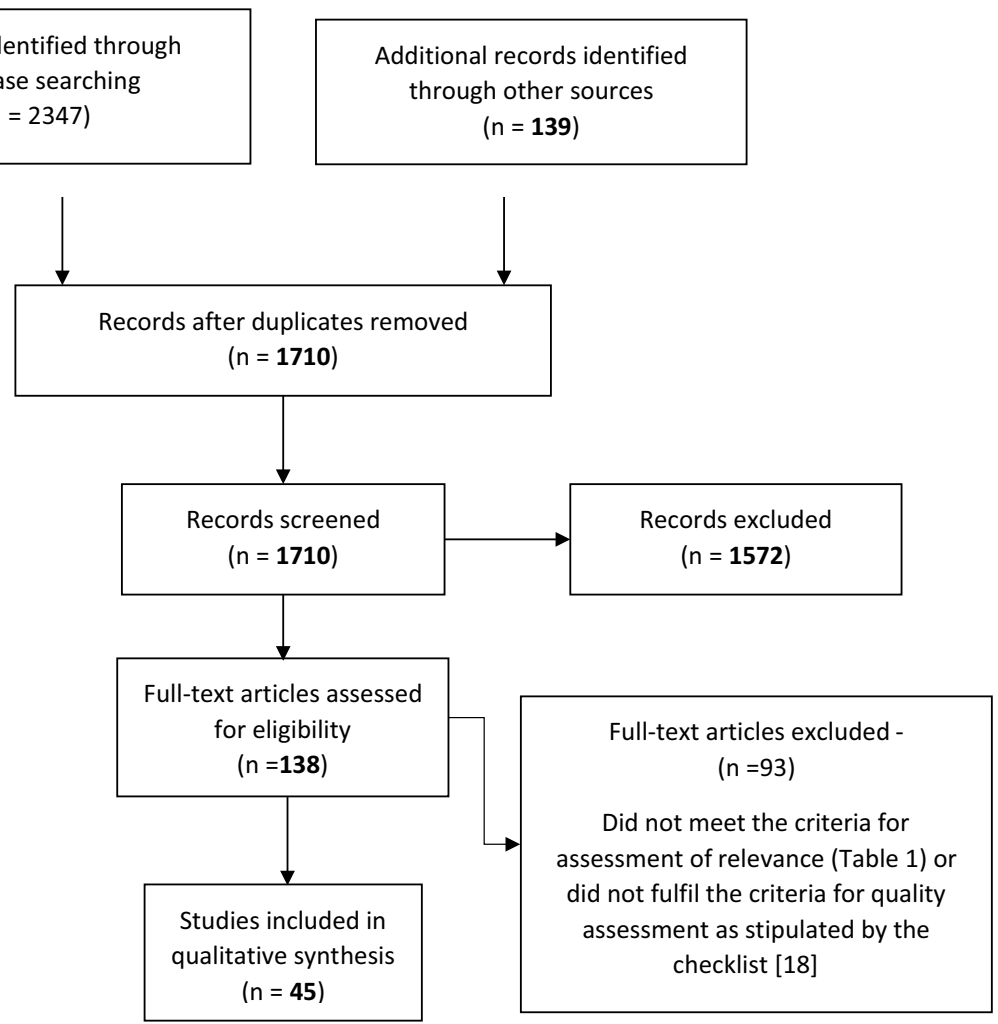

Fig. 1 PRISMA flow chart

staff considered likely to be involved in organ retrieval. $58 \%$ did not use a coherent concept of death consistently. $19 \%$ had a concept consistent with a 'higher brain' definition of death. Joffe et al. [22] surveyed 218 US neurologists regarding their understanding of BD. $48 \%$ equated irreversible loss of consciousness with death. Many also believed that persistence of brain-mediated hormonal function was not compatible with a diagnosis of BD. In a study by DuBois et al. [23] 63\% of participants agreed to organ retrieval from patients with 'higher brain' death.

In Europe, Floden et al. [9] surveyed 702 Swedish intensive care nurses. Less than half trusted the clinical diagnosis of brain death without additional imaging techniques. In a recent survey of 146 Spanish nurses, Lomero et al. [24] found that $69 \%$ equated BD with death.

In the Middle East, Alsaied et al. [10] surveyed 418 healthcare workers in Qatar. While a majority supported organ donation, less than half equated BD with death of the person. Cohen et al. [25] surveyed 2336 healthcare professionals involved in organ retrieval in Israel. $78.9 \%$ regarded BD as a valid criterion for determining death. Increasing age, higher professional status and working in ICU correlated with acceptance of BD. Acceptance correlated with greater comfort in the OD process. El Safi et al. [26] surveyed 434 allied health students in Saudi Arabia. Only 44\% supported deceased OD, though 83\% supported living OD. $49 \%$ did not trust medical staff regarding the diagnosis of BD. Nasrollahzadeh et al. [27] surveyed 130 Iranian ICU nurses. $67 \%$ accepted BD as death.

In Asia, in a Malaysian survey of medical and nursing staff [28], 83.8\% accepted the concept of BD. Of those who did not, most cited either religious reasons or claimed there was insufficient scientific evidence to support the concept. In a 2015 Chinese study of 476 doctors and nurses [29], only $50.7 \%$ considered a hypothetical BD patient dead, $51.9 \%$ would withdraw support and only $40.6 \%$ would support organ retrieval.

In Australia, Marck et al. [30] surveyed 811 Australian emergency department clinicians. $86 \%$ accepted BD as death. 


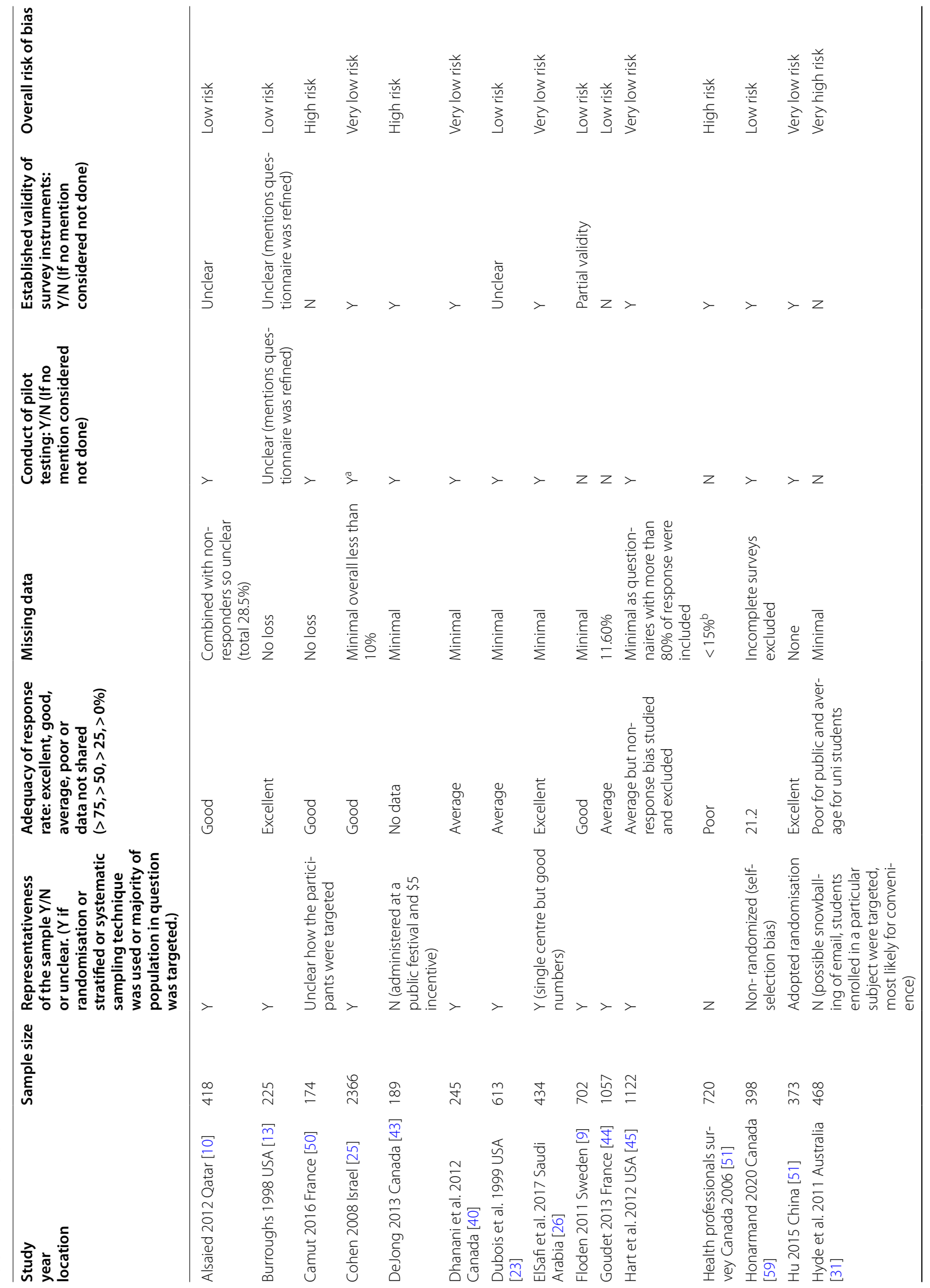




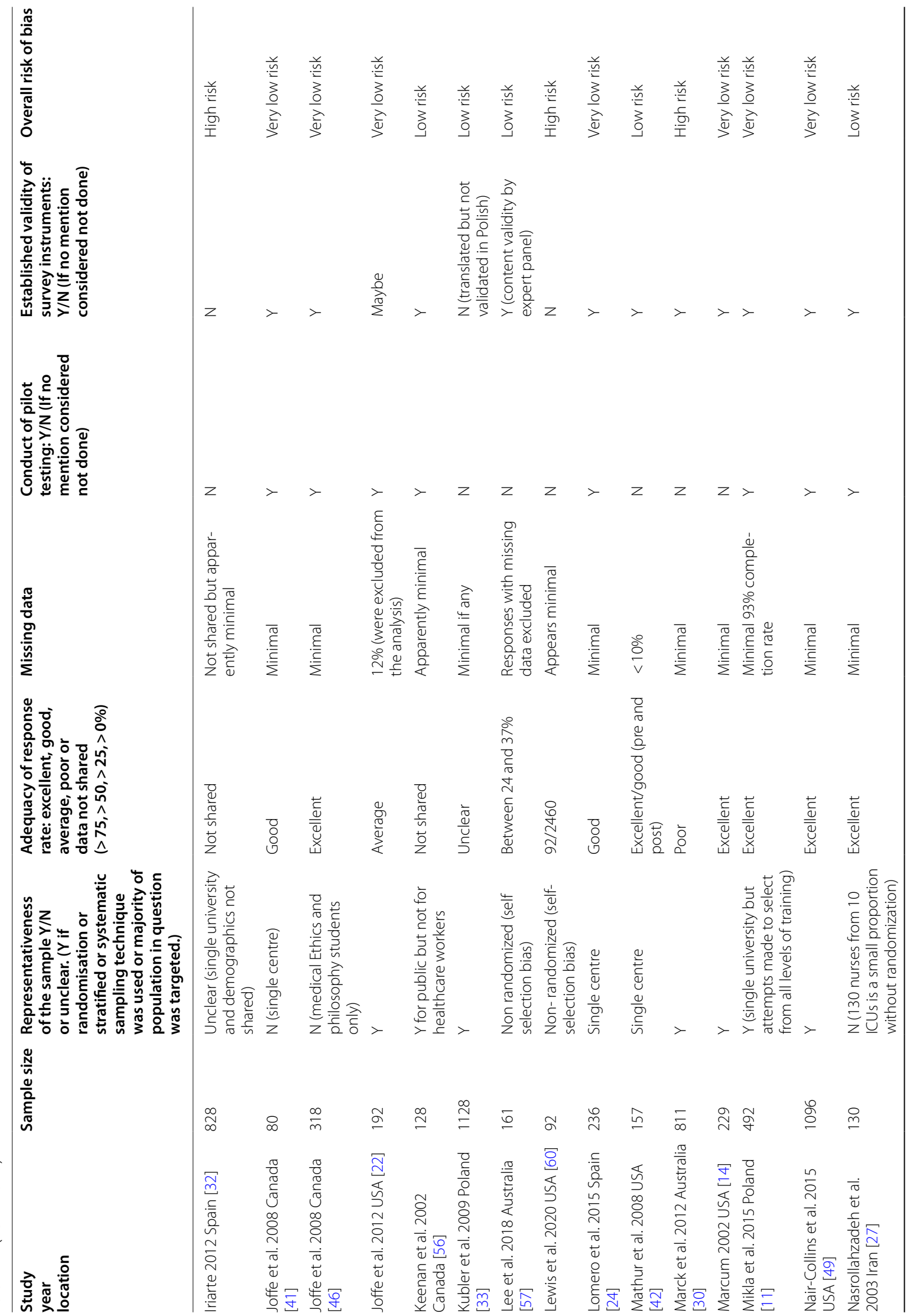




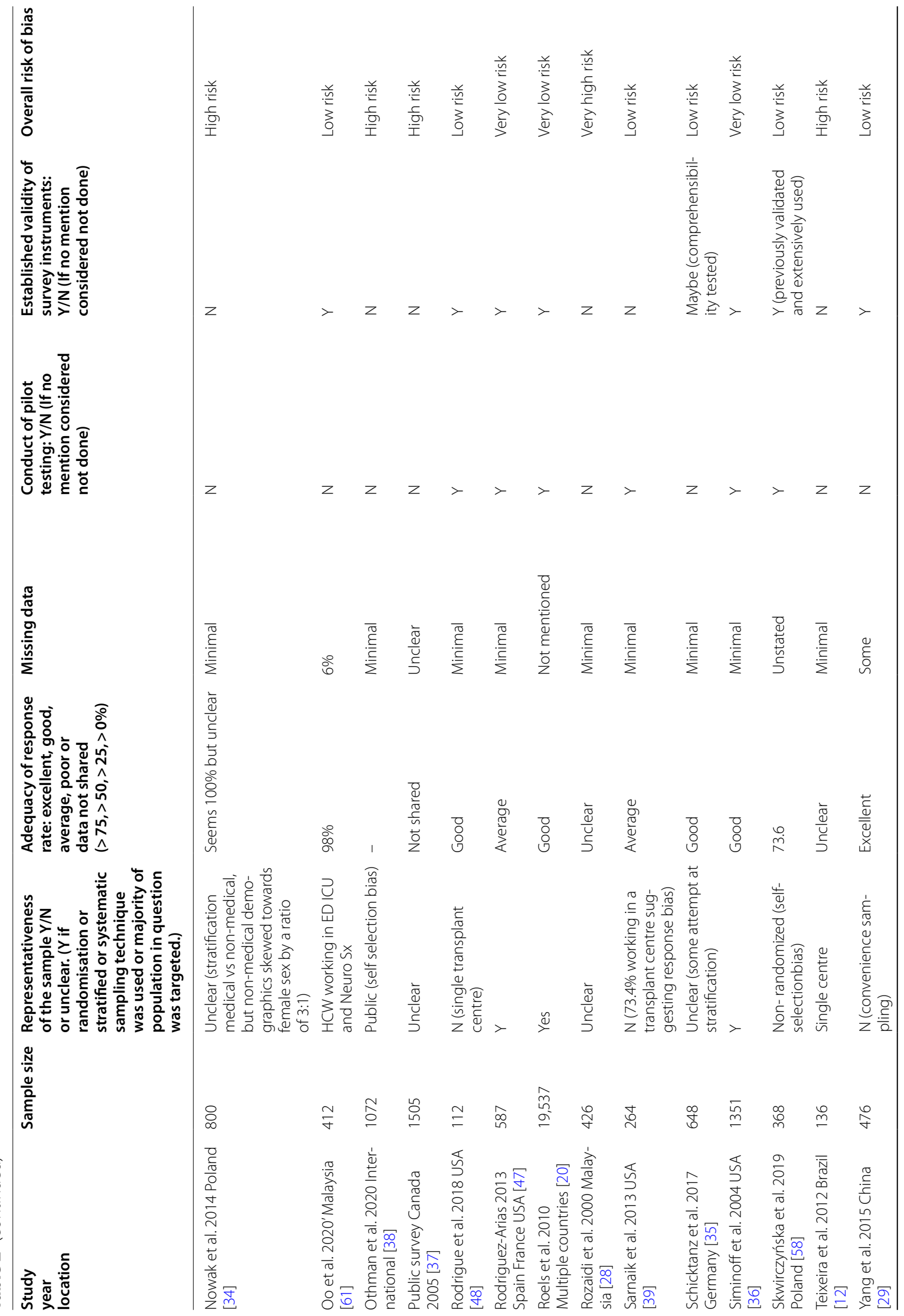




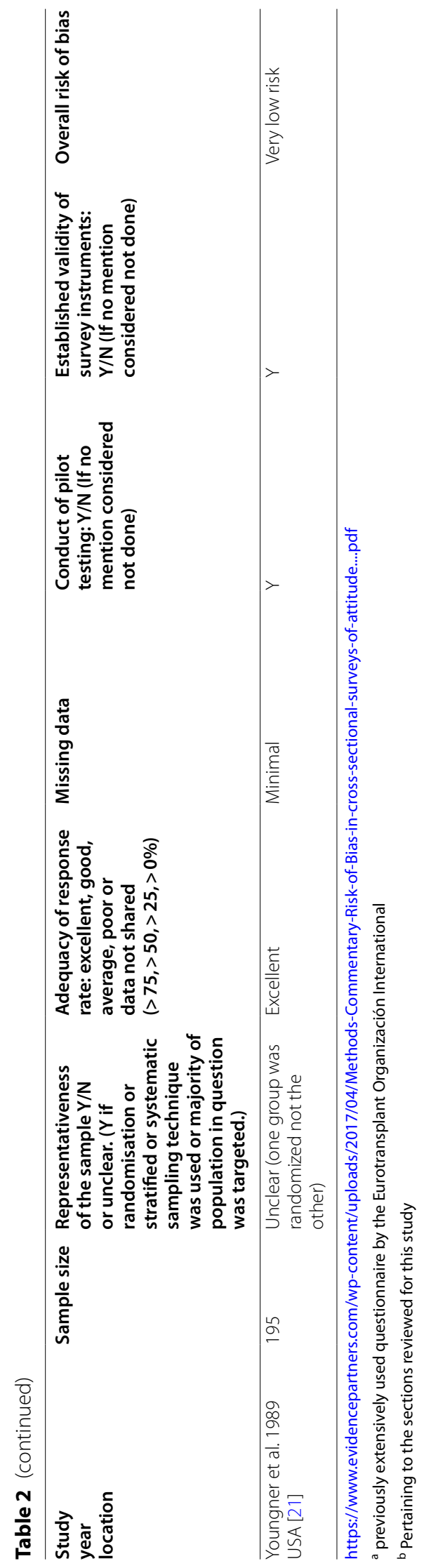




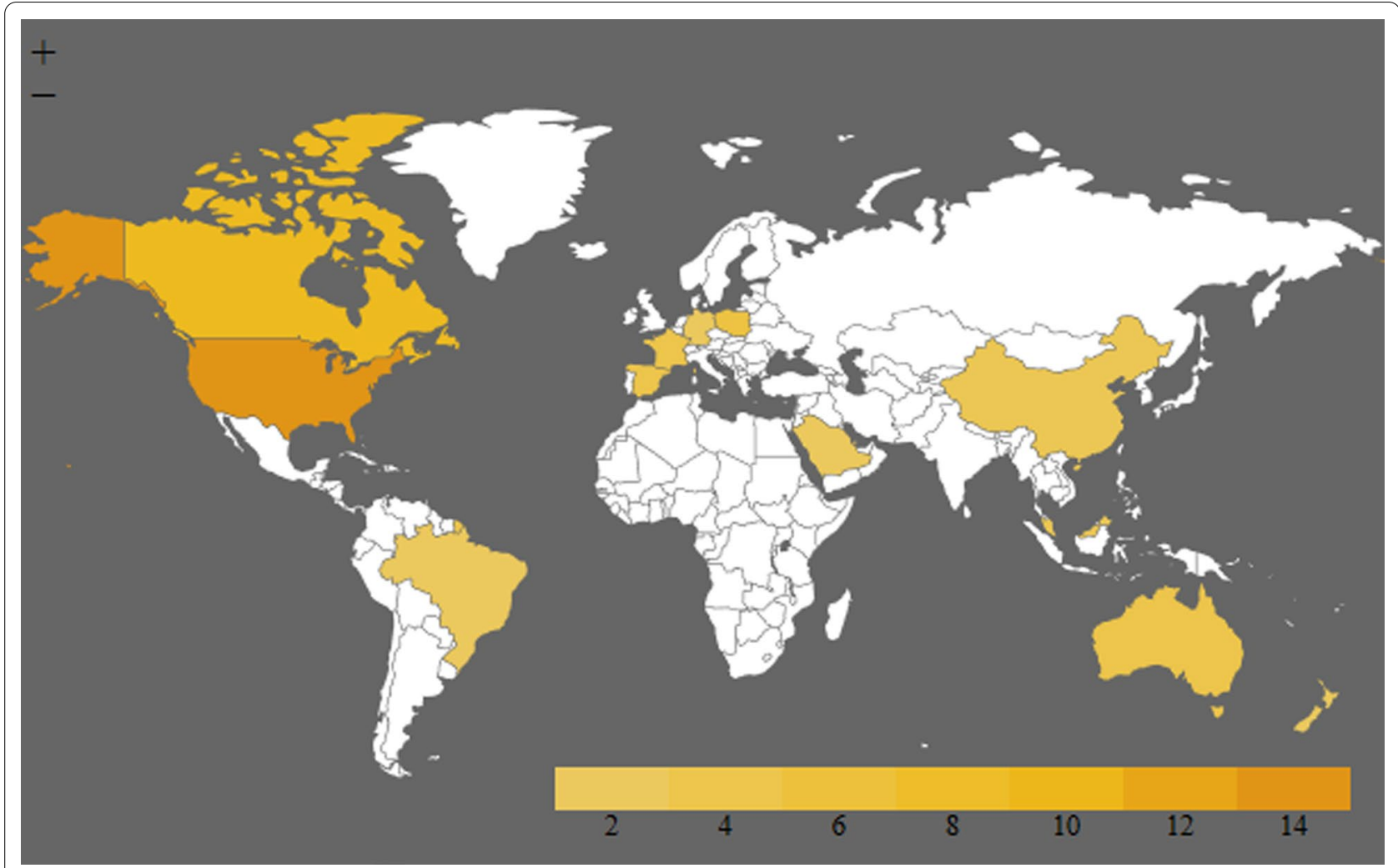

Fig. 2 Geographical distribution of studies identified

\section{Studies involving university students}

In a survey of 468 Australian university students and members of the general public by Hyde et al. [31], more than $30 \%$ of respondents unwilling or undecided about OD believed that BD patients had potential for recovery, while only $10 \%$ of willing donors agreed with this. Iriarte et al. [32] surveyed 536 Spanish university students. Less than $1 / 3$ of non-medical students identified $\mathrm{BD}$ as death, and even among final year medical students, only $2 / 3$ accepted BD as death.

Three Polish studies have addressed this question. Kubler et al. [33] surveyed 989 Polish university students. $48 \%$ believed a hypothetical BD patient was still alive, and half overall supported OD. In a study by Mikla et al. [11] of 492 Polish nursing students, $75 \%$ accepted BD as death. Nowak et al. [34] found that $85 \%$ of Polish medical students and $54 \%$ of non-medical students equated BD with death. Investigators also found high levels of mistrust of the diagnostic criteria for $\mathrm{BD}$ and for the skill and objectivity of doctors making the diagnosis.

In a 2017 German survey of medical and economics university students by Schicktanz et al. [35], around 44\% agreed that when a person's brain completely stops functioning, that person is dead.

\section{Studies involving the general public}

Siminoff et al. [36] conducted a telephone survey of 1351 Ohio residents in 2004. 86.2\% regarded a hypothetical BD patient as dead, while $57.2 \%$ regarded a comatose patient as dead, and $34 \%$ regarded a vegetative patient as dead.

In Brazil, Teixeira et al. [12] found that $77 \%$ of hospital patients interviewed did not think of brain death as death, and there was no statistical correlation between respondents' education and their understanding of brain death. As in Nowak's study of Polish students [34], high levels of mistrust in the diagnosis of brain death was also found. $26.5 \%$ did not trust and $55.1 \%$ partially trusted the diagnosis of brain death. Likewise, in a 2005 study undertaken by the Canadian Council for Donation and Transplantation [37], 20\% of respondents believed doctors might prematurely declare death in order to obtain organs for transplantation.

Othman et al. [38] studied 1072 people in 30 counties. In their study, respondents were more likely to accept circulatory death as death of the person than for brain death $(87.9 \pm 19.7 \%$ vs $84.1 \pm 22.7 \%, P=0.004)$. However, this was not reflected in a difference in acceptance of OD. 
Table 3 Included studies and overview of themes explored

\begin{tabular}{|c|c|c|c|c|c|c|c|}
\hline Author/year & $\mathrm{n}$ & $\begin{array}{l}\text { Target population } \\
\text { studied }\end{array}$ & Country & $\begin{array}{l}\text { Belief in brain } \\
\text { death criteria }\end{array}$ & $\begin{array}{l}\text { Belief in } \\
\text { DCDD } \\
\text { criteria }\end{array}$ & $\begin{array}{l}\text { Dead } \\
\text { donor } \\
\text { rule }\end{array}$ & $\begin{array}{l}\text { Ante mortem } \\
\text { interventions/ } \\
\text { consent }\end{array}$ \\
\hline Alsaied 2012 [10] & 418 & $\mathrm{HCW}$ & Qatar & $\checkmark$ & & & \\
\hline Burroughs 1998 [13] & 225 & Public & USA & $\checkmark$ & & & \\
\hline Camut 2016 [50] & 174 & $\mathrm{HCW}$ & France & $\checkmark$ & & & $\checkmark$ \\
\hline Cohen 2008 [25] & 2366 & $\mathrm{HCW}$ & Israel & $\checkmark$ & & & \\
\hline DeJong 2013 [43] & 189 & Public & Canada & & $\checkmark$ & $\checkmark$ & \\
\hline Dhanani et al. 2012 [40] & 245 & HCW & Canada & & $\checkmark$ & & $\checkmark$ \\
\hline Dubois et al. 1999 [23] & 613 & $\mathrm{HCW}$ & USA & $\checkmark$ & $\checkmark$ & & \\
\hline ElSafi et al. 2017 [26] & 434 & Students & Saudi Arabia & $\checkmark$ & & & \\
\hline Floden 2011 [9] & 702 & $\mathrm{HCW}$ & Sweden & $\checkmark$ & & & \\
\hline Goudet 2013 [44] & 1057 & HCW & France & & $\checkmark$ & & $\checkmark$ \\
\hline Hart et al. 2012 [45] & 1122 & HCW & USA & & $\checkmark$ & & \\
\hline $\begin{array}{l}\text { Health professionals } \\
\text { survey } 2006[51]\end{array}$ & 720 & HCW & Canada & & $\checkmark$ & & $\checkmark$ \\
\hline Honarmand et al. [59] & 398 & HCW & Canada & & & & $\checkmark$ \\
\hline Hu 2015 [55] & 373 & $\mathrm{HCW}$ & China & $\checkmark$ & & & \\
\hline Hyde et al. 2011 [31] & 468 & Public \& Students & Australia & $\checkmark$ & & & \\
\hline Iriarte 2012 [32] & 828 & Students & Spain & $\checkmark$ & & & \\
\hline Joffe et al. 2008 [22] & 80 & $\mathrm{HCW}$ & Canada & & $\checkmark$ & & \\
\hline Joffe et al. 2008 [46] & 318 & Students & Canada & & $\checkmark$ & & \\
\hline Joffe et al. 2012 [41] & 192 & $\mathrm{HCW}$ & USA & $\checkmark$ & & & \\
\hline Keenan et al. 2002 [56] & 128 & HCW and Public & Canada & & $\checkmark$ & & \\
\hline Kubler et al. 2009 [33] & 1128 & HCW \& Students & Poland & $\checkmark$ & & $\checkmark$ & \\
\hline Lee et al. [57] & 161 & $\mathrm{HCW}$ & AUS-NZ & & & & $\checkmark$ \\
\hline Lewis et al. 2020 [60] & 92 & HCW & USA & $\checkmark$ & & & \\
\hline Lomero et al. 2015 [24] & 236 & HCW & Spain & $\checkmark$ & & & \\
\hline Mathur et al. 2008 [42] & 157 & $\mathrm{HCW}$ & USA & & $\checkmark$ & & \\
\hline Marck et al. 2012 [30] & 811 & HCW & Australia & $\checkmark$ & & & \\
\hline Marcum 2002 [14] & 229 & $\mathrm{HCW}$ & USA & $\checkmark$ & & & \\
\hline Mikla et al. 2015 [11] & 492 & Students & Poland & $\checkmark$ & & & \\
\hline $\begin{array}{l}\text { Nair-Collins et al. } 2015 \\
\text { [49] }\end{array}$ & 1096 & Public & USA & $\checkmark$ & & $\checkmark$ & \\
\hline $\begin{array}{l}\text { Nasrollahzadeh et al. } \\
2003 \text { [27] }\end{array}$ & 130 & HCW & Iran & $\checkmark$ & & & \\
\hline Nowak et al. 2014 [34] & 800 & Students & Poland & $\checkmark$ & & & \\
\hline Oo et al. 2020 [61] & 412 & $\mathrm{HCW}$ & Malaysia & $\checkmark$ & & & \\
\hline Othman et al. [38] & 1072 & Public & $\begin{array}{l}\text { Europe and North } \\
\text { America }\end{array}$ & $\checkmark$ & $\checkmark$ & & \\
\hline Public survey 2005 [37] & 1505 & Public & Canada & & $\checkmark$ & & $\checkmark$ \\
\hline Rodrigue et al. 2018 [48] & 112 & HCW & USA & & $\checkmark$ & & \\
\hline Rodriguez-Arias 2013 [47] & 587 & $\mathrm{HCW}$ & Spain France USA & $\checkmark$ & & & \\
\hline Roels et al. 2010 [20] & 19,537 & $\mathrm{HCW}$ & multiple countries & $\checkmark$ & & & \\
\hline Rozaidi et al. 2000 [28] & 426 & $\mathrm{HCW}$ & Malaysia & $\checkmark$ & & & \\
\hline Sarnaik et al. 2013 [39] & 264 & HCW & USA & $\checkmark$ & & $\checkmark$ & $\checkmark$ \\
\hline Schicktanz et al. 2017 [35] & 648 & Students & Germany & $\checkmark$ & & $\checkmark$ & \\
\hline Siminoff et al. 2004 [36] & 1351 & Public & USA & $\checkmark$ & & $\checkmark$ & \\
\hline $\begin{array}{l}\text { Skwirczyńska et al. } 2019 \\
\text { [58] }\end{array}$ & 368 & $\mathrm{HCW}$ & Poland & $\checkmark$ & $\checkmark$ & & \\
\hline Teixeira et al. 2012 [12] & 136 & Public & Brazil & $\checkmark$ & & & \\
\hline Yang et al. 2015 [29] & 476 & HCW \& Students & China & $\checkmark$ & & & \\
\hline
\end{tabular}


Table 3 (continued)

\begin{tabular}{lllllll}
\hline Author/year & $\mathbf{n}$ & $\begin{array}{l}\text { Target population } \\
\text { studied }\end{array}$ & Country & $\begin{array}{l}\text { Belief in brain } \\
\text { death criteria }\end{array}$ & $\begin{array}{l}\text { Belief in } \\
\text { DCDD } \\
\text { criteria }\end{array}$ & $\begin{array}{l}\text { Dead } \\
\text { donor } \\
\text { rule }\end{array}$ \\
\hline Youngner et al. $1989[21]$ & 195 & HCW & USA & $\checkmark$ & $\begin{array}{l}\text { Ante mortem } \\
\text { interventions/ } \\
\text { consent }\end{array}$ \\
\hline
\end{tabular}

\section{Attitudes to DCDD}

Fourteen studies examined attitudes to DCDD (Table 3). Once again, the large majority involved healthcare workers, with only 4 studies surveying the general public and one involving medical students.

The most common issue identified was concern with the duration of circulatory arrest required to determine death.

Sarnaik et al. [39] surveyed 273 American paediatric intensivists. $41 \%$ expressed concern that the timing of death during DCDD could not be precisely determined. Dhanani et al. [40] surveyed 250 Canadian intensivists. They reported variability in the determination of death after cardiac arrest, concerns regarding autoresuscitation, and a perceived need for standardisation of practice.

Joffe et al. [41] surveyed 80 paediatricians in a Canadian university children's hospital. Almost half expressed concern that a hypothetical DCDD patient could not be regarded as unequivocally dead after 5 min of circulatory arrest. In a survey of 93 US paediatric critical care nurses by Mathur et al. [42], 14\% believed that a 5-min observation period after circulatory arrest was insufficient to declare death.

De Jong et al. [43] interviewed 189 members of the general public in Canada, asking how long after circulatory arrest a hypothetical patient could be regarded as dead. After 5 min of arrest, $53 \%$ agreed that death had occurred and $42 \%$ agreed that the heart could be removed for transplantation. Where the heart had stopped 'mere seconds ago', 46\% still agreed death had occurred, but only $24 \%$ agreed with removal of the heart.

Three studies reported more general concerns with the diagnosis of death in DCDD or the DCDD process. Goudet et al. [44] surveyed 1057 French healthcare professionals. 54\% reported ethical concerns with DCDD, with junior intensive care doctors reporting the greatest level of concern. Hart et al. [45] carried out a US national survey of 684 intensivists and 438 ICU nurses. Around $14.5 \%$ of both groups expressed concern that the management of DCDD patients could create professional role conflicts, though $33.8 \%$ of physicians and $55.1 \%$ of nurses believed DCDD could potentially improve end-of-life care. Joffe and colleagues [46] surveyed 320 university students from a number of disciplines, finding that they too were not confident that a hypothetical DCDD patient was actually dead. Rodriguez-Arias et al. [47] interviewed
587 healthcare professionals involved in organ retrieval in Spain, France and the US. Main themes identified were that BD was regarded as a more reliable standard for the diagnosis of death in organ donors than circulatory death, and, while most regarded organ retrieval from brain dead patients as morally acceptable, DCDD was much more contentious.

In a study by Rodrigue et al. [48] in the US, $15 \%$ of the critical care staff were not sure if a patient is dead at the time of organ recovery in DCDD cases.

\section{Attitudes to the DDR}

Six studies directly or indirectly raised issues concerning the DDR (Table 3). Only 3 involved the general public, all North American.

In the Polish student study by Kubler [33] 34\% of respondents supported OD from non-brain-dead unconscious hypothetical patients. In the German study by Schicktanz et al. [35], 28\% of students supported a'higher brain' definition of death. In Siminoff's Ohio study [36], $33.5 \%$ of the general public supported OD in cases they did not regard as dead.

In De Jong et al's survey of the Canadian public [43], $49 \%$ of respondents agreed that the DDR should be abandoned and 58\% agreed that different definitions of death should be used for organ donation. However, in Sarnaik's [39] study of US intensivists, $84 \%$ supported the principle of the DDR.

Nair-Collins[49] surveyed 1096 members of the American general public in 2015, using a scenario involving an irreversibly comatose patient, where it was explicitly stated that organ donation would cause death. $71 \%$ of respondents agreed it should be legal for patients to donate organs in this situation. Of those generally willing to donate their organs, $76 \%$ agreed they would donate in these circumstances.

\section{Ante-mortem interventions and consent}

We identified 6 studies that examined attitudes to antemortem interventions in DCDD. Only one involved members of the general public.

Camut et al. [50] surveyed 173 French healthcare professionals in 2013 regarding the provision of non-therapeutic intensive care in a case of massive stroke, for the purpose of organ donation. $93 \%$ of respondents believed this was acceptable, but $75 \%$ required advance consent 


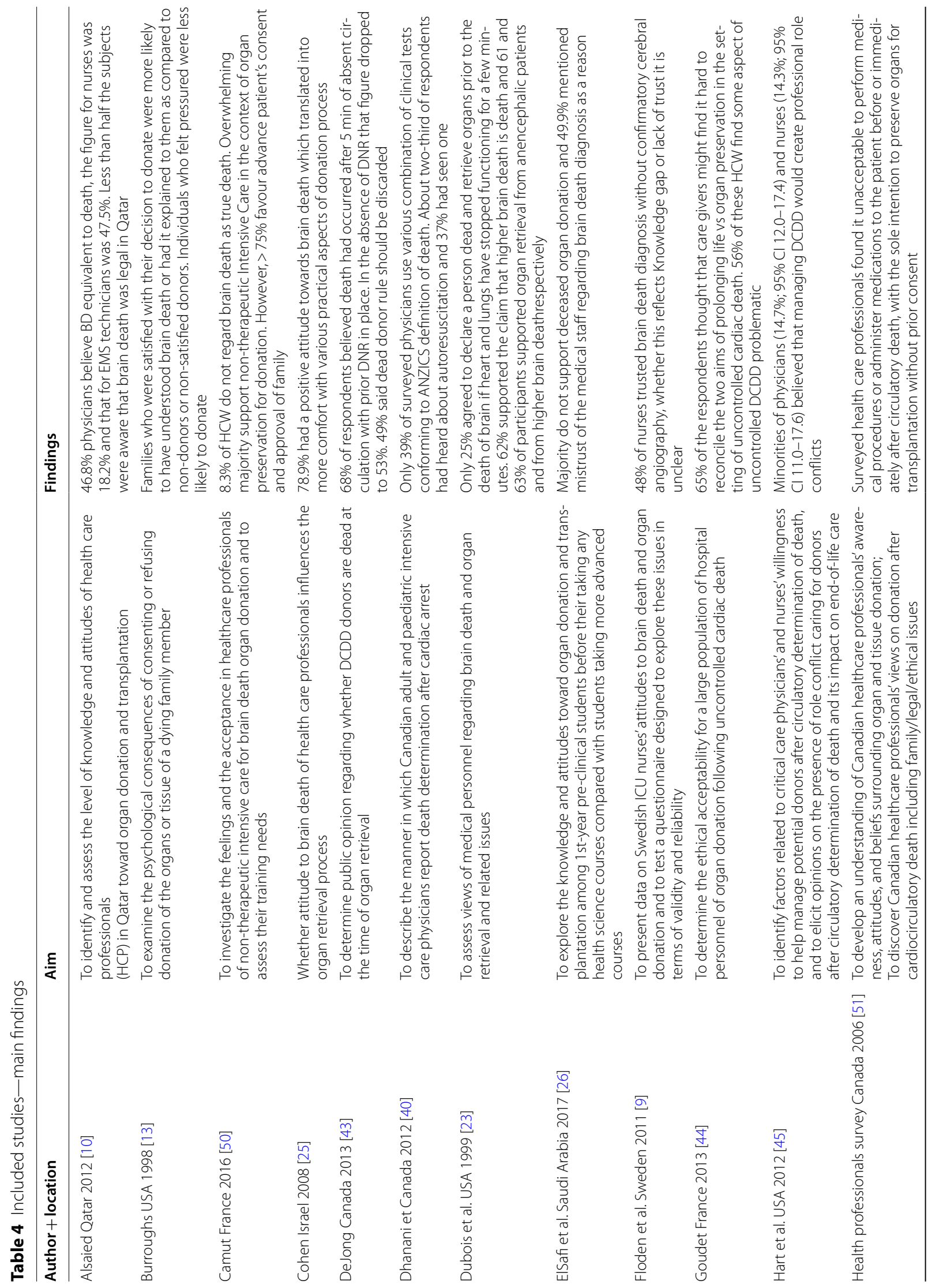




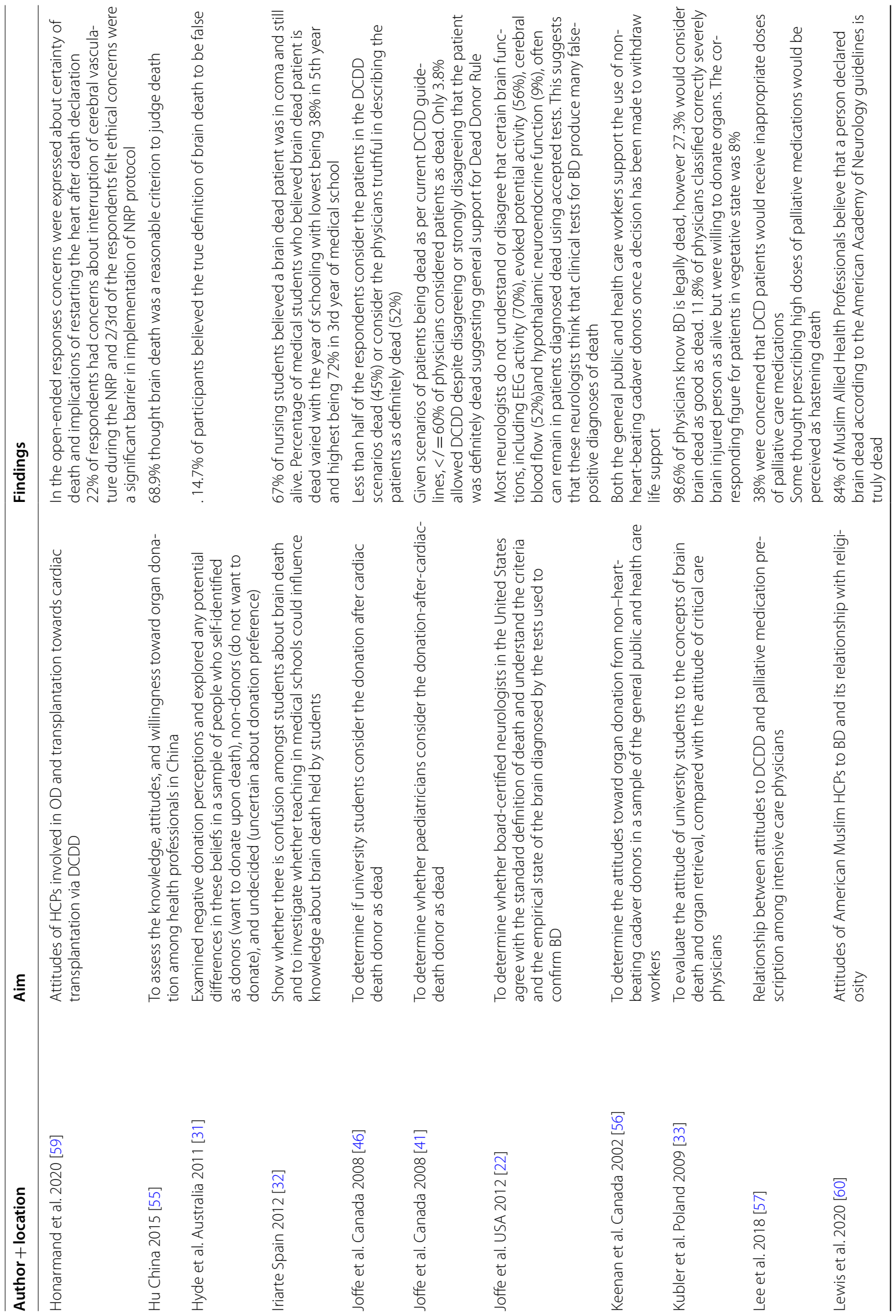




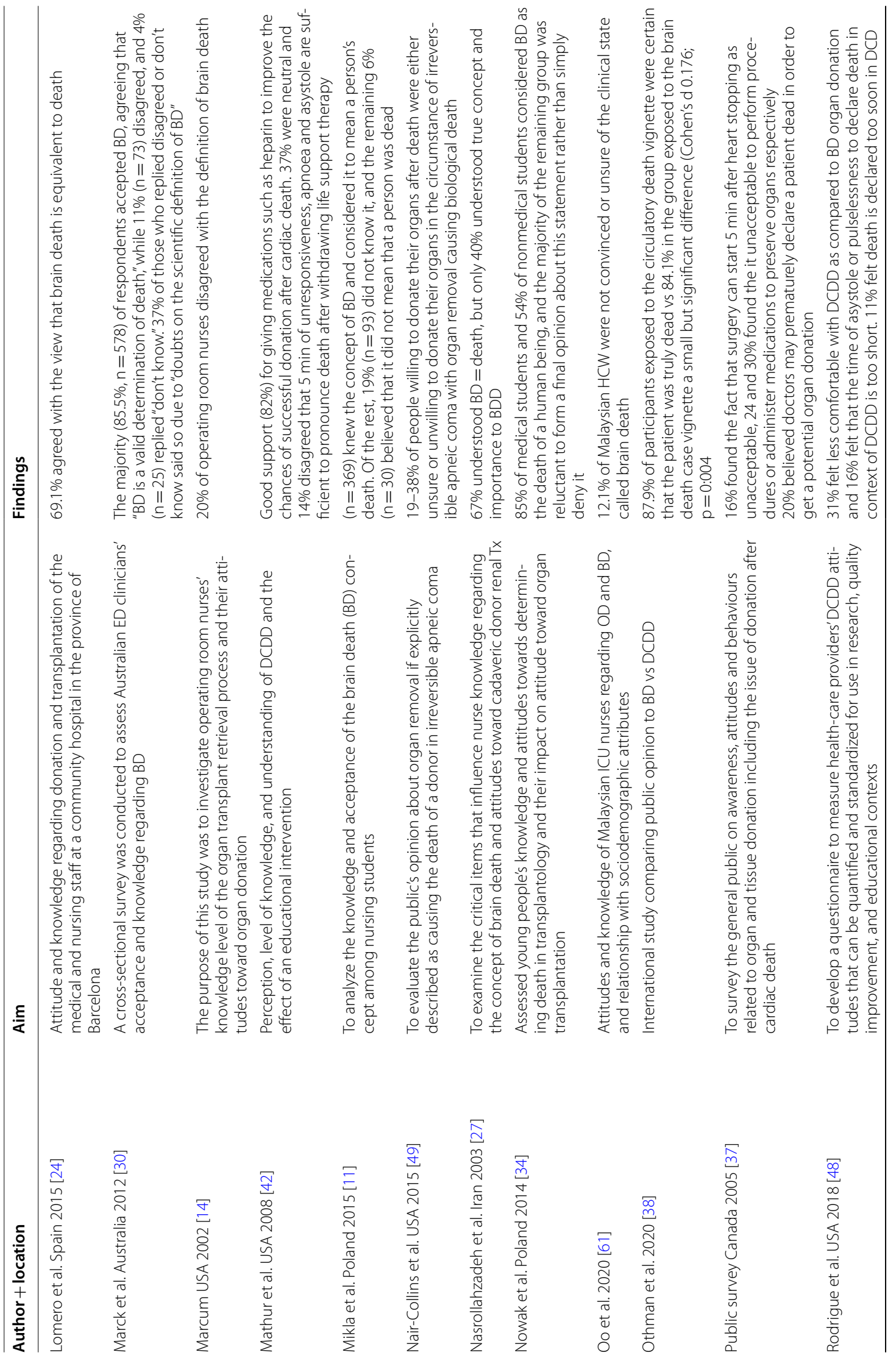




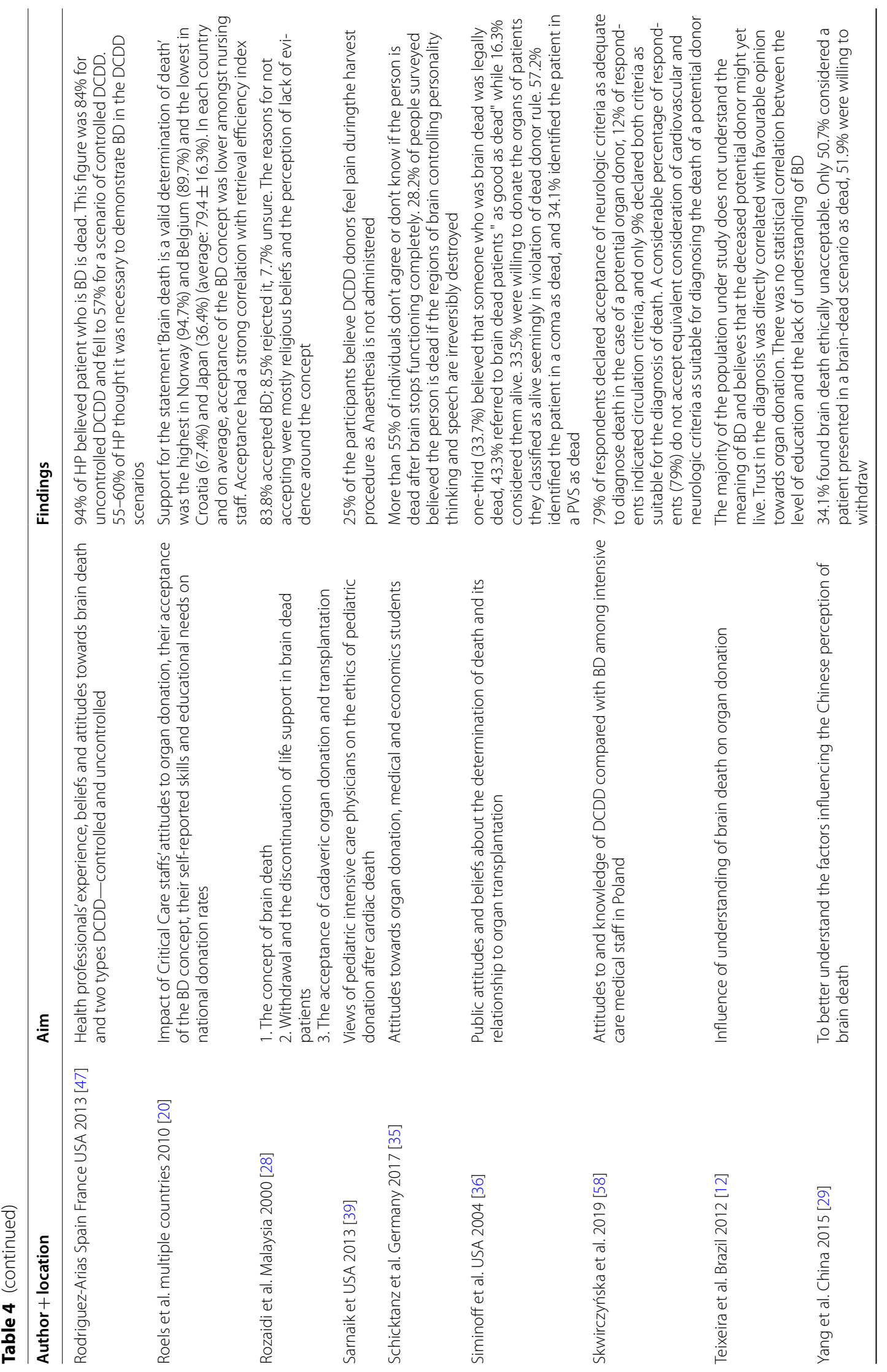


of the patient and their family. The findings of a Canadian survey of health care professionals [51] echoed similar views-a majority of them found it unacceptable to perform medical procedures or administer medications to the patient before or immediately after circulatory death, with the sole intention to preserve organs for transplantation without prior consent.

In the Canadian Council for Donation and Transplantation study [37] only half the respondents found medications and procedures provided before death to maintain organs acceptable.

Support for interventions seemed to vary depending on the degree of invasiveness. In the study by Dhanani et al. [40], while there was overwhelming support for heparin infusion to preserve organs, that support diminished when cannulation was considered.

In a study by Goudet et al. [44] $42 \%$ of respondents did not want cannulation of the patient for organ preservation without prior family consent. An important significant minority regarded this as an unacceptable alteration of body integrity. Similar findings were noted in the study by Sarnaik et al. [39].

\section{Discussion}

This scoping review examined evidence regarding acceptance of and attitudes towards the concepts of BD, DCDD and the DDR, and how these relate to attitudes and decision-making regarding organ donation. We found that there is strong support for OD, but a range of views regarding $\mathrm{BD}, \mathrm{DCDD}$ and the DDR-both within and between different countries and populations-with persisting concerns regarding the extent to which BD represented death of the person. In one study, organ donation rates of a country correlated positively with acceptance of BD [20]. A substantial proportion of respondents in several studies appeared to favour a 'higher brain' concept of death, while others were comfortable with OD, even if it was the proximate cause of death $[35,36]$.

A striking feature of our review was the paucity of studies examining attitudes of the public, with a large majority involving healthcare workers of various types. A second, smaller group of studies focussed on university students, mainly comprising medical and nursing students. This lack of more broadly-based information is important, because it may help to explain disparity between the high reported rates of support for OD and the relatively low rates of consent reported in many jurisdictions.

Another notable feature was the tendency to ascribe rejection of or uncertainty about these concepts of death to a knowledge deficit that could or should be addressed by further education-a well-recognised assumption in health care and public policy debates known as the 'knowledge deficit model' of the public understanding of 
science. This is a problematic assumption both because it fails to recognise that differences of opinion may represent genuine differences in values and because there is considerable data suggesting that while knowledge and education may predict the strength of attitudes to scientific matters, positivity of attitudes are poorly correlated with knowledge [52].

While the diagnosis of BD has been widely accepted medically and legally as equivalent to death of the person for over 50 years, our review revealed that $20-40 \%$ of participants in most studies do not accept that BD is truly equivalent to death of the person. Some studies showed that age, education and background in healthcare were associated with a higher likelihood of accepting BD as equivalent to death, but these features were not predictive. Religious or cultural factors on opinion could be implicated in some studies, but not in all.

Some studies [36] found sizeable proportions of respondents who considered that severe brain injury not meeting the accepted criteria for BD was sufficient to determine death. Even among American neurologists, when asked to give a reason why brain death is equivalent to death, $48 \%$ chose a 'higher brain' explanation [22]. This is an important finding, as such levels of brain injury are not accepted as the basis for determining death in any jurisdiction.

In comparison to studies examining attitudes to organ donation after BD (DBD), we found far fewer studies examining attitudes to DCDD. Importantly, most of these studies found less support for DCDD than DBD. The principal issue of concern appears to be the timing of determination of death, with around half the respondents to most surveys expressing discomfort with the idea that a few minutes of cardiorespiratory arrest were adequate to determine the death of an individual. Once again, however, these studies were predominantly conducted in healthcare workers rather than members of the general public.

Lack of confidence in medical procedures or in medical practitioners around the diagnosis of death were frequently noted in relation to both BD and DCDD. In studies that examined confidence in the methods used to diagnose $\mathrm{BD}$, a substantial number of respondents did not have full confidence in either the doctors making the diagnosis, or in the diagnostic criteria or tests used. In the case of DCDD, the most common issue identified was lack of confidence regarding whether the very short time after which death was being determined following cessation of circulation, could be considered accurate. The potential for a conflict of interest between the desire to procure organs for transplantation and the requirement to provide appropriate palliative care to a patient at end of life was also noted as a concern in DCDD cases.
Only a few studies explicitly reported attitudes to the DDR, and in all, considerable proportions of respondents supported retrieval of organs for transplantation from patients with severe brain injury who were not BD. In these studies, the proposition put to respondents was that brain death was not determined prior to organ donation, or donation was not occurring following cardiorespiratory standstill as in DCDD. This is an important, and for some possibly an uncomfortable finding, as it suggests that for many people, life with severe brain dysfunction and poor prospects for a sentient and relatively independent future would be considered as being of less 'value' than donating organs and thus dying. In this setting the physiological and clinical criteria by which death is determined in medical practice would appear to have little relevance. Of interest, the study with the lowest level of acceptance of organ donation in patients without BD was the only study focussed entirely on medical professionals, suggesting perhaps that the principal discomfort with these concepts lies within the healthcare community.

Antemortem interventions were only considered in 6 studies, 5 limited to healthcare professionals, and all found levels of discomfort, with most respondents insisting this was only acceptable with explicit consent, especially for invasive procedures. In this context, it is interesting to note the study by Shahrestani et al. [53], who interviewed 30 clinicians involved in transplantation from 8 countries. From their thematic analysis, they concluded that ante-mortem interventions were acceptable only where distress for the donor and family are not increased, the interventions did not cause harm, patient and family have a strong drive to successful donation, and the interventions are evidence-based.

\section{Strengths and limitations}

We conducted a comprehensive search to review all English language, quantitative studies involving attitudes and beliefs surrounding BD and DCDD in the context of organ donation. A scoping review allows a broader range of studies to be included than a systematic review. While it does not provide the same statistical rigor, it is preferable where it is not appropriate to aggregate divergent datasets for meta-analysis. Our review was guided by the PRISMA protocol to ensure our sample captured all the relevant scholarship. Our review consolidates a vast international literature on attitudes toward $\mathrm{BD}$ and DCDD in the context of organ donation. It brings to light the divergent attitudes about how death is determined before organ donation, despite strong support for organ transplantation generally.

These results are limited by a few factors. A significant limitation was the tendency for studies to conflate 
attitudes with knowledge. We suggest that attitudes relate more to socio-cultural values than factual knowledge, though we identified no data to support this. NonEnglish literature was excluded from our review but could communicate different perspectives than the ones reported herein. Healthcare workers directly involved in organ donation, whose attitudes are more relevant to clinical practice, have been poorly studied. We propose to address this in future studies. Finally, notwithstanding our assessment of bias, the findings of the studies in this review could still be subject to biases inherent in all questionnaire based studies [54]

\section{Conclusion}

The idea that death is a prerequisite to the removal of vital organs for transplantation has been an ethical cornerstone of medical practice since transplantation began. However, there is a fundamental tension between the need to minimise ischaemic time to ensure successful transplantation, and the need for death to be confidently diagnosed before transplantation can proceed. This tension has largely driven changes in the way death is diagnosed in this context, resulting in the widespread adoption of the concepts of $\mathrm{BD}$ and, more recently, circulatory death and DCDD. These innovations have been promulgated by those directly involved in transplantation and organ donation, with little effort to assess their acceptance among the health professions, or the general community.

Our review suggests that a considerable proportion of healthcare workers, as well as members of the general public, have doubts about the conceptual and clinical validity of $B D$ and DCDD as ways to determine death, especially before organ donation. These doubts are usually ascribed to ignorance about $\mathrm{BD}$ and/or DCDD, or to 'unjustifiable' or ideological opposition to them. However, the fact that these concerns are expressed across different populations and cultural contexts and are voiced even by experts in the field, including intensive care professionals, suggests that these explanations may be unfounded.

Likewise, a considerable proportion of people appear to feel prognosis (meaning the likelihood of a return to meaningful or quality life following brain injury), rather than the diagnosis of death per se, is most important regarding decisions about organ donation and the cessation of ICU support. This suggests the need to (re)engage the public in discussions about the values and goals of medical care and move away from the idea that debates about end-of-life care can be simply resolved by clarifying and promulgating different definitions of death.

Finally, studies examining attitudes to perimortem interventions suggest that these are only acceptable following explicit consent, and where the consequences for the donor are minimal.

Further studies are needed to examine the complex interplay of factual knowledge and values-based attitudes regarding death in determining the overall acceptance of organ donation.

\section{Appendix}

\begin{tabular}{ll}
\hline Brain death (BD) & $\begin{array}{l}\text { A definition of death as complete } \\
\text { and irreversible loss of brain func- } \\
\text { tion, even when the circulation } \\
\text { and breathing are maintained by } \\
\text { external means } \\
\text { The use of electrical stimulation to } \\
\text { restore heart contractions when } \\
\text { they have ceased }\end{array}$ \\
Defibrillation & $\begin{array}{l}\text { A definition of death as the com- } \\
\text { plete cessation of heart and respira- } \\
\text { tory activity beyond a defined time } \\
\text { indeath }\end{array}$ \\
interval \\
An ethical principle stipulating that \\
vead donor rule (DDR) \\
for transplans should only be removed \\
has been declared dead \\
Damage to organs and tissues that \\
develops progressively when they \\
are deprived of blood flow \\
The spontaneous re-commence- \\
ment of cardiac and/or respiratory \\
activity some time after these have \\
ceased \\
Auto-resuscitation
\end{tabular}

\section{Supplementary Information}

The online version contains supplementary material available at https://doi. org/10.1186/s12910-021-00734-z.

Additional file 1. Literature Search Strategy.

\section{Acknowledgements}

None.

Authors' contributions

DW-S undertook the database searches. AR produced the tables and figures. GS wrote the initial manuscript. All authors reviewed abstracts and studies for inclusion and participated in review and editing of the manuscript.

\section{Funding}

This study was supported by funding provided by the Sydney Medical School Foundation. 
Availability of data and materials

Not applicable.

\section{Declarations}

\section{Ethics approval and consent to participate}

Not applicable.

\section{Consent for publication}

Not applicable.

\section{Competing interests}

Professor Kerridge was a member of the National Health and Medical Research Council's Organ Transplantation and Donation Ethical Guidelines Group (2019-20). Dr O'Leary is Co-State Medical Director, NSW Organ \& Tissue Donation Service. None of the other authors have competing interests to declare.

\section{Author details}

${ }^{1}$ Sydney Health Ethics, University of Sydney, Sydney, Australia. ${ }^{2}$ Canberra Hospital, Canberra, Australia. ${ }^{3}$ ACT Health Library, Canberra, Australia. ${ }^{4}$ School of Medicine, Deakin University, Geelong, Australia. ${ }^{5}$ Royal Prince Alfred Hospital, Sydney, Australia. ${ }^{6}$ South East Sydney Local Health District, Sydney, Australia. ${ }^{7}$ Law School, University of Sydney, Sydney, Australia. ${ }^{8}$ Haematology Department, Royal North Shore Hospital, St Leonards, Australia. ${ }^{9}$ St George Hospital, Gray Street, Kogarah, NSW 2217, Australia.

Received: 25 August 2021 Accepted: 23 November 2021 Published online: 18 December 2021

\section{References}

1. Lewis A, Greer D. Current controversies in brain death determination. Nat Rev Neurol. 2017;13(8):505-9.

2. Verheijde JL, Rady MY, Potts M. Neuroscience and brain death controversies: the elephant in the room. J Relig Health. 2018;57(5):1745-63.

3. Smith M. Brain death: time for an international consensus. $\mathrm{Br} J$ Anaesth. 2012;108(s1):i6-9.

4. Lewis A, Greer D. Medicolegal complications of apnoea testing for determination of brain death. J Bioeth Inq 2018:15(3):417-28.

5. Pope T. Brain death and the law: hard cases and legal challenges. Hastings Cent Rep. 2018;48(Suppl 4):S46-8.

6. Greer DM, Shemie SD, Lewis A, et al. Determination of brain death/ death by neurologic criteria: the world brain death project. JAMA 2020;324:1078-97.

7. Joffe AR, Hansen G, Tibballs J. The world brain death project: the more you say it does not make it true. J Clin Ethics. 2021;32(2):97-108.

8. DeVita MA, Snyder JV, Grenvik A. History of organ donation by patients with cardiac death. Kennedy Inst Ethics J. 1993;3(2):113-29.

9. Floden AP, Persson L, Rizell M, et al. Attitudes to organ donation among Swedish ICU nurses. J Clin Nurs. 2011:20(21-22):3183-95.

10. Alsaied O, Bener A, Al-Mosalamani Y, Mour B. Knowledge and attitudes of health care professionals toward organ donation and transplantation. Saudi J Kid Dis Transpl. 2012;23(6):1304-10.

11. Mikla M, Rios A, Lopez-Navas A, et al. Brain death: is it a misunderstood concept among nursing students in the South of Poland? Transplant Proc. 2015:47(9):2578-80.

12. Teixeira RKC, Gonçalves TB, Silva JA. Is the intention to donate organs influenced by the public's understanding of brain death? Rev Bras Ter Intensiva. 2012;24(3):258-62

13. Burroughs TE, Hong BA, Kappel DF, Freedman BK. The stability of family decisions to consent or refuse organ donation: would you do it again? Psychosomatic Med. 1998;60(2):156-62.

14. Marcum, L., Attitudes of operating room nurses towards organ donation. Thesis, Faculty of Department of Nursing 2002; Clarkson College, Nebraska. UMI 1408248

15. Munn Z, Peters MDJ, Stern C, et al. Systematic review or scoping review? Guidance for authors when choosing between a systematic or scoping review approach. BMC Med Res Methodol. 2018;18(1):143.
16. Peters MDJ, Marnie C, Tricco A, et al. Updated methodological guidance for the conduct of scoping reviews. JBI Evidence Synth. 2020;18(10):2119-26.

17. Strech D, Synofzik M, Marckmann G. Systematic reviews of empirical bioethics. J Med Ethics. 2008;34(6):472-7.

18. Roever L. Critical appraisal of a questionnaire study. evidence based medicine and practice 2016; 1(2).

19. Agarwal A, Guyatt G, Busse JW, Methods Commentary: risk of Bias in crosssectional surveys of attitudes and practices 2019; Evidence Partners. https:// www.evidencepartners.com/resources/methodological-resources/risk-of-biascross-sectional-surveys-of-attitudes-and-practices. Accessed 31 July 2021.

20. Roels L, Spaight C, Smits J, Cohen B. Critical care staffs'attitudes, confidence levels and educational needs correlate with countries' donation rates: data from the Donor Action database. Transpl Int. 2010;23(8):842-50.

21. Youngner SJ, Landefeld CS, Coulton CJ et al., 'Brain death'and organ retrieval. A cross-sectional survey of knowledge and concepts among health professionals. JAMA. 1989:261(15):2205-10.

22. Joffe AR, Anton NR, Duff JP, de Caen A. A survey of American neurologists about brain death: understanding the conceptual basis and diagnostic tests for brain death. Ann Intens Care. 2012;2(1):4.

23. DuBois JM. Ethical assessments of brain death and organ procurement policies: a survey of transplant personnel in the United States. J Transpl Coord. 1999:9(4):210-8

24. Lomero MM, et al. Knowledge and attitude of health personnel at the Garraf Health Consortium regarding donation and transplantation. Transplant Proc. 2015:47(8):2318-21.

25. Cohen J, et al. Attitude of health care professionals to brain death: influence on the organ donation process. Clin Transplant. 2008;22(2):211-5.

26. Elsafi $\mathrm{SH}, \mathrm{Al}-\mathrm{Adw}$ ani MM, Jubran $\mathrm{KM}$, et al. Factors influencing the willingness of allied health students to donate organs or tissues. Transplant Proc. 2017:49(6):1215-20

27. Nasrollahzadeh D, Siavosh H, Ghods AJ. Intensive care unit nurses'attitudes and knowledge toward brain death and cadaveric renal transplantation in iran. Transpl Proc. 2003;35(7):2545.

28. Rozaidi SW, Sukro J, Dan A. The health care professional's attitudes towards brain death and cadaveric organ transplantation: the influence of cadaveric donor and transplantation programs-a Malaysian survey. Med J Malaysia. 2000;55(4):478-85

29. Yang $Q$, Fang $Y$, Cheng $Q$, et al. Acceptance in theory but not practiceChinese medical providers' perception of brain death. Neuroethics. 2015:8(3):299-313.

30. Marck CH, Weiland TJ, Neate SL, et al. Australian emergency doctors' and nurses' acceptance and knowledge regarding brain death: a national survey. Clin Transplant. 2012;26(3):E254-60.

31. Hyde MK, Wihardjo KR, White KM. Do the myths still exist? Revisiting people's negative beliefs about organ donation upon death. Psychol Health Med. 2012;17(5):530-41.

32. Iriarte J, et al. Brain death: is it an appropriate term? Neurología (English Edition). 2012;27(1):16-21.

33. Kubler A, Lipinska-Gediga M, Kedziora J, Kubler M. Attitudes to brain death and organ procurement among university students and critical care physicians in Poland. Transpl Proc. 2009:41(5):1473-6.

34. Nowak E, Pfitzner R, Koźlik P, et al. Brain death versus irreversible cardiac arrest-the background and consequences of young people's opinions on stating death in Polish transplantology. Transplant Proc. 2014;46(8):2530-4.

35. Schicktanz S, Pfaller L, Hansen SL, Boos M. Attitudes towards brain death and conceptions of the body in relation to willingness or reluctance to donate: results of a student survey before and after the German transplantation scandals and legal changes. J Public Health (09431853). 2017;25(3):249-56.

36. Siminoff $L A$, Burant $C$, Youngner SJ. Death and organ procurement: public beliefs and attitudes. Kennedy Inst Ethics J. 2004;14(3):217-34.

37. Organ and Tissue Donation Public Opinion Survey. 2005. https://profession aleducation.blood.ca/sites/msi/files/GPSurvey_Topline_Report Sep05.pdf. Accessed 31 July 2021

38. Othman M, Dutta A, Kondziella D. Public opinion and legislations related to brain death, circulatory death and organ donation. J Neurol Sci. 2020. https://doi.org/10.1016/j.jns.2020.116800.

39. Sarnaik AA, et al. Views of pediatric intensive care physicians on the ethics of organ donation after cardiac death. Crit Care Med. 2013;41(7):1733-44.

40. Dhanani SW, Ward R, Hornby L, et al. Survey of determination of death after cardiac arrest by intensive care physicians. Crit Care Med. 2012:40(5):1449-55. 
41. Joffe AR, Anton NR, Decaen AR. Survey of pediatricians' opinions on donation after cardiac death: are the donors dead? Pediatrics. 2008;122(5):e967-74.

42. Mathur MT, Taylor S, Tiras K, Wilson M, Abd-Allah S. Pediatric critical care nurses' perceptions, knowledge, and attitudes regarding organ donation after cardiac death. Ped Crit Care Med. 2008;9(3):261-9.

43. DeJong, J., et al., A survey to determine public opinion regarding whether short periods of absent circulation count as death and should allow vital organ donation. In: American Journal of Respiratory and Critical Care Medicine. Conference: American Thoracic Society International Conference, ATS, 2013. 187(Meeting Abstracts).

44. Goudet V, Albouy-Laty M, Migeot V, et al. Does uncontrolled cardiac death for organ donation raise ethical questions? An opinion survey. Acta Anaesthesiol Scand. 2013;57(10):1230-6.

45. Hart JL, Kohn R, Halpern SD. Perceptions of organ donation after circulatory determination of death among critical care physicians and nurses: a national survey. Crit Care Med. 2012;40(9):2595-600.

46. Joffe AR, Byrne R, Anton NR, Decaen AR. Donation after cardiac death: a survey of university student opinions on death and donation. Intensive Care Med. 2009;35(2):240-7

47. Rodriguez-Arias D, Tortosa JC, Burant, et al. One or two types of death? Attitudes of health professionals towards brain death and donation after circulatory death in three countries. Med Health Care Philos. 2013;16(3): 457-67.

48. Rodrigue JR, Luskin R, Nelson H. Measuring critical care providers' attitudes about controlled donation after circulatory death. Prog Transplant. 2018;28(2):142-50.

49. Nair-Collins M, Green SR, Sutin AR. Abandoning the dead donor rule? A national survey of public views on death and organ donation. J Med Ethics. 2015;41(4):297-302.

50. Camut $S$, Bauman A, DuBois $V$, et al. Non-therapeutic intensive care for organ donation: a healthcare professionals' opinion survey. Nurs Ethics. 2016;23(2):191-202.

51. Canadian Council for Donation and Transplantation. Health Professional Awareness and Attitudes on Organ and Tissue Donation and Transplantation 2006. https://professionaleducation.blood.ca/sites/msi/files/SurveyHealth-Prof.pdf. Accessed 31 July 2020.

52. Allum N, Sturgis P, Tabourazi D, Brunton-Smith I. Science knowledge and attitudes across cultures: a meta-analysis. Public Underst Sci. 2008;17(1):35-54.

53. Shahrestani, S., Hawthorne, Wayne J et al. Clinicians' attitudes and perspectives on ante-mortem interventions in deceased organ donation. Transplantation. 2018; 102.

54. Choi BC, Pak AW. A catalog of biases in questionnaires. Prev Chronic Dis. 2005;2(1):A13

55. Hu DH, Huang $\mathrm{H}$. Knowledge, attitudes, and willingness toward organ donation among health professionals in China. Transplantation. 2015;99(7):1379-85.

56. Keenan SPH, Hoffmaster B, Rutledge F, et al. Attitudes regarding organ donation from non-heart-beating donors. J Crit Care. 2002;17(1):29-38.

57. Lee YY, Ranse K, Silvester W, et al. Attitudes and self-reported end-oflife care of Australian and New Zealand intensive care doctors in the context of organ donation after circulatory death. Anaes Intens Care. 2018;46(5):488-97.

58. Skwirczynska E, Prekwa A, Ostrowski M. Donors after circulatory deaththeme of present or a future? The research of west Pomeranian province in Poland. Transplantation. 2018;102(7):S440.

59. Honarmand K, Parsons JL, Basmaji J, et al. Attitudes of healthcare providers towards cardiac donation after circulatory determination of death: a Canadian nation-wide survey. Can J Anesth. 2020;67:301-12.

60. Lewis A, Kitamura E, Padela Al. Allied Muslim healthcare professional perspectives on death by neurologic criteria. Neurocrit Care. 2020;33(2):347-57.

61. Oo WL, Ong JS, Foong JW, et al. Knowledge and attitudes of healthcare professionals and the impact on willingness to donate organs: A tertiary hospital survey. Singapore Med J. 2020;61(3):154-61.

\section{Publisher's Note}

Springer Nature remains neutral with regard to jurisdictional claims in published maps and institutional affiliations.

Ready to submit your research? Choose BMC and benefit from:

- fast, convenient online submission

- thorough peer review by experienced researchers in your field

- rapid publication on acceptance

- support for research data, including large and complex data types

- gold Open Access which fosters wider collaboration and increased citations

- maximum visibility for your research: over 100M website views per year

At BMC, research is always in progress.

Learn more biomedcentral.com/submissions 